\title{
The Development of POTENSIA; The Android-Based Psychological Application for Mapping and Assessments of Student Mental Health During the COVID-19 Pandemic
}

\author{
https://doi.org/10.3991/ijim.v15i16.25147 \\ Zadrian Ardi ${ }^{1(凶)}$, Hendra Hidayat ${ }^{1}$, Ifdil Ifdil ${ }^{1}$, Yan Guspriadi², Siti Azizi Fauziyyah ${ }^{2}$ \\ ${ }^{1}$ Universitas Negeri Padang, Padang, Indonesia \\ ${ }^{2}$ Potensia Institute, Padang, Indonesia \\ zadrian@fip. unp. ac.id
}

\begin{abstract}
Students experience various essential changes related to their psychological conditions during their education in college. Students' adaptability to the demands of these changes will give birth to new skills for the next stage of psychological development. However, academic stress, social problems, career, and personal-emotional problems can hinder the productivity and development of students in terms of mental health. This issue increased with the new-normal life during the COVID-19 pandemic, which also impacted the education process. For this reason, it is necessary to have a mobile-based online psychological assessment to map the mental health conditions of students during the pandemic. This study aims to develop and validate an Android-based online psychological assessment application to map students' mental health conditions. This study involved ten experts in counseling and software development, five counselors, and 638 users of the POTENSIA application. According to application development needs, data analysis using Aiken's V coefficient test, Confirmatory Factor Analysis (CFA), and Rasch Model Analysis. The results of the study prove that the application is considered valid and practical to use. The effectiveness of the application is considered very good in mapping the mental health conditions of students.
\end{abstract}

Keywords - android-based applocation, mental health, college student, COVID-19 pandemic

\section{Introduction}

College students must be individuals with logical and planning abilities at the higher education stage [1-3]. To achieve this, students experience changes in their roles, functions, and psychological development. The transition from high school to higher education creates psychological dynamics changes [4, 5]. Aspects that are determinants of psychological change and development such as cultural changes, new environments, living separately from parents, significant academic atmosphere changes, and college choices can be reasons for early future career choices [5-8]. For this reason, students should have basic knowledge and insight about these changing conditions. 
This insight also increases students' adaptability to these changes by increasing skills which are a stage of life. The adaptation is an individual process in responding to changes that occur in the environment that can affect the individual's physical and psychological $[9,10]$. The process of adaptation of students to the new environment in higher education, is characterized by four types of adaptation, academic adaptation, adaptation to the social environment, adaptation to personal-emotional, and adaptation to institutions [10]. The adaptation process in higher education is also a process that requires coping skills in adjusting to various fields [11]. Students' adaptability to these changes will form new skills that can be used in the next stage of life $[12,13]$. This is a manifestation of ability to face challenges while studying at university.

As a country with a demographic bonus of productive age, education in Indonesia demands quality from every student it accepts [14-16]. Various improvements to the quality of learning and curriculum are the focus of higher education, including strengthening students' academic atmosphere and research [17, 18]. However, the emergence of the Covid-19 virus outbreak, which has become a worldwide pandemic, has resulted in very drastic lifestyle changes $[19,20]$. The phenomenon in the field states that students in lectures face problems. Problems in the education process at universities are ineffective discussions, less active in attending lectures, lack of interaction between lecturers and students, difficulties in attending practical classes, and the psychological burden caused by the online learning process [21-23]. The emergence of the Covid-19 pandemic requires students to improve their adaptability to new educational patterns in higher education.

However, not a few of the students experienced academic pressure, the study load was overloaded, and the learning atmosphere was dense, impacting students' mental health conditions $[20,24,25]$. Like physical health, mental health is significant for humans. Mental health can be shown by individuals who are free from various symptoms of mental disorders. Thus, mentally healthy students can live their lives normally and adapt to managing stress to deal with the problems they will encounter $[26,27]$. Meanwhile, students who experience mental disorders tend to bring up negative cognitions so that they can cause depression and disrupt the lecture process [28].

Mental health problems experienced by students also impact low academic achievement and delays in completing studies [27, 29]. This problem makes it difficult for students to adjust to the new system like the network in access to web learning (e-learning) which must be stable, lecture materials are not as straightforward as direct lectures, and academic schedules are delayed and delayed [30-33]. In addition to problems directly related to the learning process, there are also stressors from the students' daily lives themselves [34]. The impact of development experienced by students during COVID-19 encourages the emergence of mental health problems. Mental health problems that have developed during this pandemic are stress, anxiety, and even depression. For students, this pandemic causes stress and nervousness, marked by changes in interactions in the learning process and daily life $[35,36]$.

Efforts to manage students' mental health conditions should be carried out more optimally [33, 34, 37]. In the current state of development of mobile technology, handling student mental health conditions can be done quickly, efficiently, and effectively [38]. Therefore, handling student mental health problems should be preceded by a quick and efficient mapping of mental health conditions, also paying attention to health protocols. 
The mapping of mental health conditions considers the speed of obtaining data from the assessment and the possibility of appropriate counseling interventions. This effort requires the precision of the assessment coupled with the flexibility of the medium. Then, counseling intervention as the end of maintaining mental health conditions must be based on baseline data obtained from the assessment [16, 39]. Therefore, it is necessary to have an accurate assessment and suitable media to obtain precise data about the mental health condition of students during the COVID-19 pandemic.

One of the steps in meeting the target of appropriate counseling interventions for students' mental health conditions during the COVID-19 pandemic is to develop an online psychological assessment application. The focus of this research is to develop and validate an Android-based online psychological assessment application called POTENSIA.

\section{Research methods}

\subsection{Research design}

POTENSIA application development is carried out using the ADDIE Model method as seen in Figure 1. The use of this model adapts to the needs and objectives of this application, which focuses on developing an online student needs assessment platform that will be used as the basis for planning counseling interventions in universities.

The process of data analysis based on a needs study is carried out first to obtain data on the acceptance of the target application for the program to be developed. This process involves a series of tests that have been carried out from 2017 to 2020. In addition, retesting is also carried out before the design process is carried out to ensure the features that will be developed in the application.

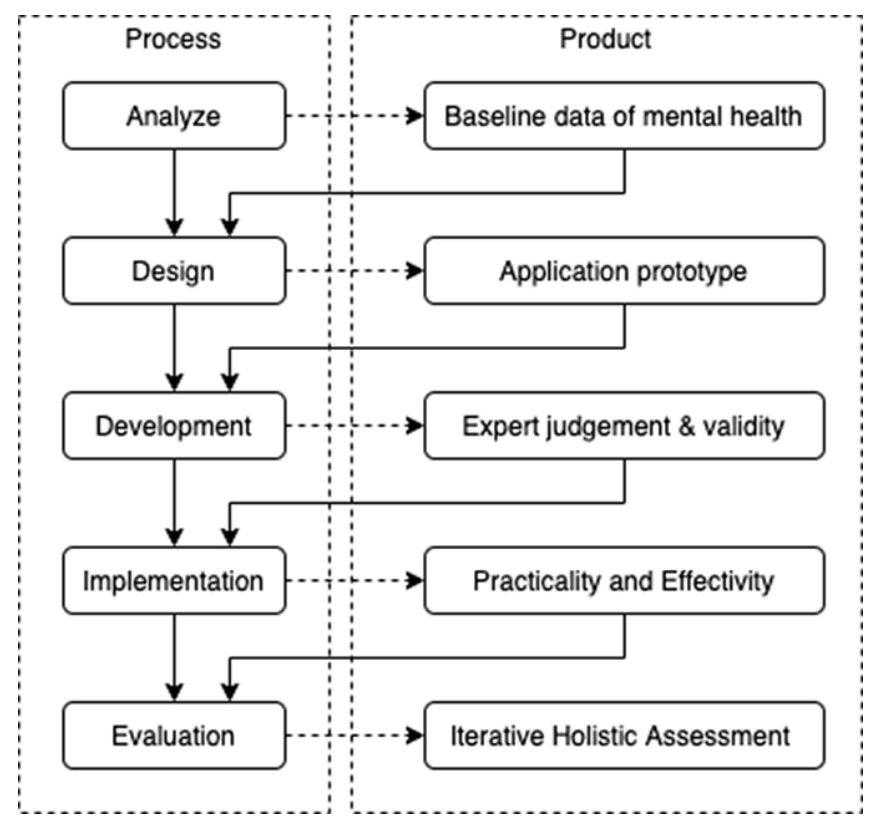

Fig. 1. The development process of POTENSIA apps 
The design stage involves a series of processes for compiling the user interface (UI) and user experience (UX) through a design application. UI and UX requirements are adjusted to the results of the previous needs assessment. By compiling the final results from UI and UX, we get an application for mental health assessment that can be accessed on Android-based devices. The development and implementation process aims to get an assessment from the expert as described in the participant section. The practicality of the application is obtained through the acceptability of the application's assessment. Furthermore, in the effectiveness test process, respondents were tested to determine the accuracy of the online assessment developed in the application. The acceptability value from the counselor's side in interpreting the assessment results in a counseling path in service planning. Finally, an evaluation process is carried out to obtain holistic assessment results and serve as a baseline for application improvement.

\subsection{Participant}

The data in this study were collected from various segments according to the type of testing carried out. At the development stage, this research involved five experts in assessment in counseling and five experts in the treatment and education-based software development. Then at the practicality measurement stage and respondents' acceptance of the application, data were obtained by involving 638 students from all over Indonesia who were randomly selected. The effectiveness of the application is carried out by testing the online assessment on the application to obtain the data accuracy coefficient. Furthermore, the measurement of acceptability in terms of interpretation of the assessment results was carried out on five counselors who made plans for counseling services.

To ensure the use of the respondent's data, the respondent was asked for a consent form for data collection and publication. This process is carried out entirely through distance as a form of anticipation of the spread of the Covid-19 virus. The data collection process was also carried out using the POTENSIA application, which the respondent first installed.

\subsection{Measurement}

This application development process involves a series of tests and instruments that adjust at each step. The instruments involved in this research are expert validation sheets, the Acceptability of Mental-Health Mobile App Survey (AMMS) [38, 39], and a measuring tool that is a feature of the application, namely the Zadrian-Ifdil Problem Checklist (ZIPC).

Measurement of the instrument's validity is carried out through the Rasch Model Analysis test to obtain the accuracy of measuring data, missing data conditions, and the ability to measure data outliers. In addition, testing using Confirmatory Factor Analysis (CFA) was also carried out to test the instrument's construct so that the data obtained did show the acceptability of the product developed robustly.

AMMS testing using Rasch Model Analysis produces a Cronbach Alpha reliability coefficient value of 0.92 . Furthermore, testing of the measured dimensions is carried 
out through unidimensionality testing. The series of dimensionality tests will have an impact on the CFA analysis. Unidimensionality testing obtained raw variance units of $50.7 \%$ with a total unexplained variable of $11.1 \%$. This condition proves that the instrument has explained more than half of the variable units in the construct measured with good precision.

Table 1. The factor loadings of AMMS measure

\begin{tabular}{|c|c|c|c|c|c|}
\hline \multicolumn{7}{|c|}{ Factor Loadings } \\
\hline Factor & Indicator & Estimate & Std. Error & z-Value & p \\
\hline Factor 1 & A1 & 0.524 & 0.116 & 4.535 & $<.001$ \\
\cline { 2 - 6 } & A2 & 0.495 & 0.059 & 8.392 & $<.001$ \\
\cline { 2 - 6 } & A3 & 0.620 & 0.060 & 10.401 & $<.001$ \\
\cline { 2 - 6 } & A4 & 0.524 & 0.063 & 8.354 & $<.001$ \\
\cline { 2 - 6 } & A5 & 0.548 & 0.060 & 9.090 & $<.001$ \\
\cline { 2 - 6 } & A6 & 0.520 & 0.054 & 9.606 & $<.001$ \\
\cline { 2 - 6 } & A7 & 0.566 & 0.054 & 10.521 & $<.001$ \\
\cline { 2 - 6 } & A8 & 0.571 & 0.051 & 11.122 & $<.001$ \\
\cline { 2 - 6 } & A9 & 0.576 & 0.054 & 10.731 & $<.001$ \\
\cline { 2 - 6 } & A10 & 0.603 & 0.048 & 12.695 & $<.001$ \\
\hline
\end{tabular}

Based on the CFA analysis from the Table 1, this measuring instrument also provides a coefficient that proves the construct it has compiled. Of all the items in the AMMS, all of them have a loading factor with a $\mathrm{p}$-value $<0.001$ with an estimated correlation coefficient that is strong enough to be excellent. This condition proves that the measuring instrument used to determine the level of acceptability of respondents to the application is proven to be good. Meanwhile, the use of the ZIPC instruments will be described in the results and discussion section.

\subsection{Development tools}

Application development involves a set of software that is based on needs. For User Interface (UI) needs, the tools used are Adobe Illustrator 2020 version 24.0.0 to get unique icon designs and application characteristics [40]. Meanwhile, for the needs of User Experience (UX) using the Sketch software version 58; where this application can consider the user's convenience in using the application [41, 42]. The coding process to build the application using Visual Code Studio version 1.56.0 using the React Native framework to build Android applications.

\subsection{Data analysis}

The acceptability of the application is obtained from an expert assessment which is then formulated and analyzed using Aiken's V. This formula will produce an index that determines whether the prototype assessed has met face validity and content validity requirements from mental health assessment experts. Testing using the Aiken's V 
formula was also carried out for counselors to determine the acceptability index within the scope of planning counseling services from online assessments.

Meanwhile, to get the value of practicality and acceptance of respondents to the developed application, an analysis was carried out using Rasch Model Analysis. Then to determine the accuracy of the online assessment developed in the application, testing was carried out through Confirmatory Factor Analysis to produce an index of construct validity and strength for each item in compiling the developed online assessment.

\section{$3 \quad$ Result and discussion}

\subsection{Main features of application}

The application development process goes through three main phases, resulting in features that support the online psychological assessment process. The first phase is the design process for the User Interface (UI) and User Experience (UX) of the application. UI development is carried out by considering the uniqueness of the application and the design convenience of the application environment. This process will produce every icon and symbol used as long as the application is running on the user's device. At the same time, UX development is carried out to create user comfort in using the application. This process is carried out by compiling each application layer with logic and algorithms that present the conditions and the actual psychological assessment process as seen in Figure 2.

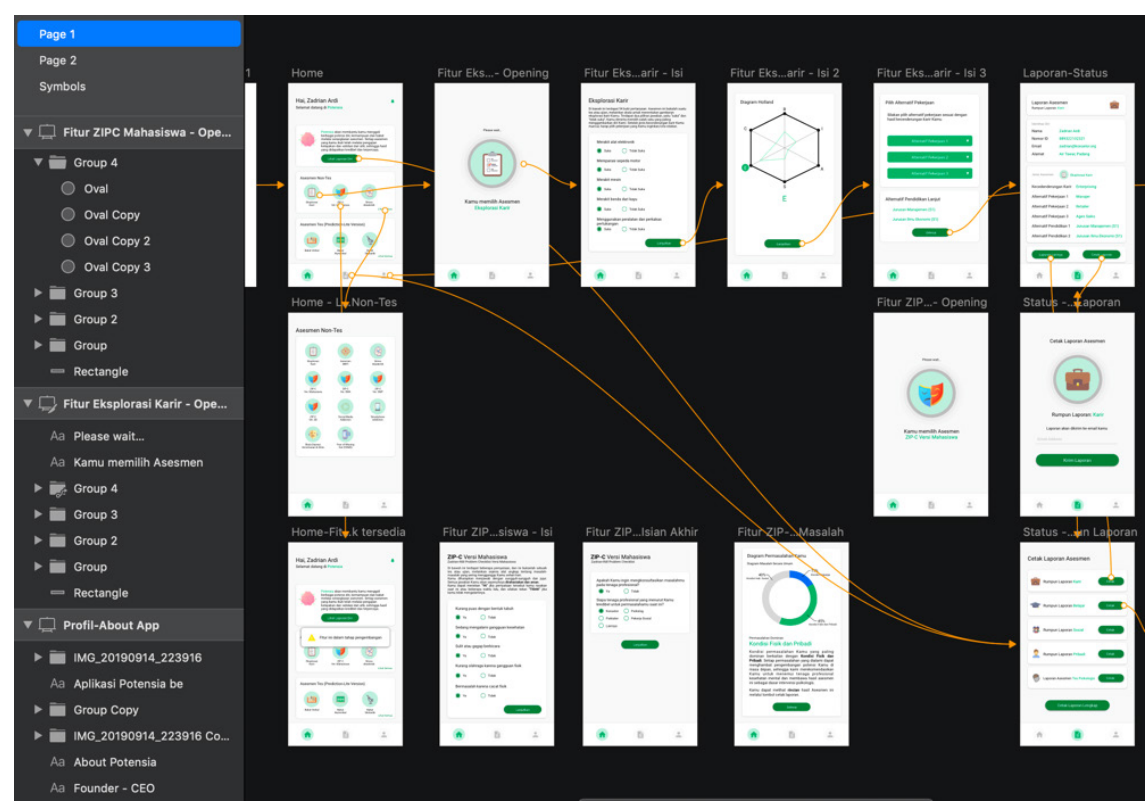

Fig. 2. The process of developing the User Interface (UI) and User Experience (UX) of the POTENTIA application 
This application consists of 4 main layers: sign up/log in and profiling, home as seen in Figure 3, assessment as seen in Figure 4, and result as seen in Figures 5 and 6. In the first layer, the user can directly see the available features. However, to be able to access these features, the user must first register. The user can access the home and the type of assessment provided by the application in the second and third layers. In the last layer, the application will provide access to view the results of the assessment.

The main feature provided by the POTENSIA application is a career exploration feature based on Holland's career theory. The assessment results will display a hexagonal graph containing the trend towards the user's career direction [43]. This assessment contains several statements that the user can select. The final results of this assessment can also be accessed by mental health professionals (such as counselors or psychologists) by entering the referral code of the professional. The next feature provided by this application is an assessment that can accurately predict the current state of mental health and problems experienced by users through the Zadrian-Ifdil Problem Checklist (ZIPC) measuring tool [44]. This measuring tool serves to map the mental health conditions and problems experienced by the user. Counselors will later use data from the mapping process in planning counseling services.

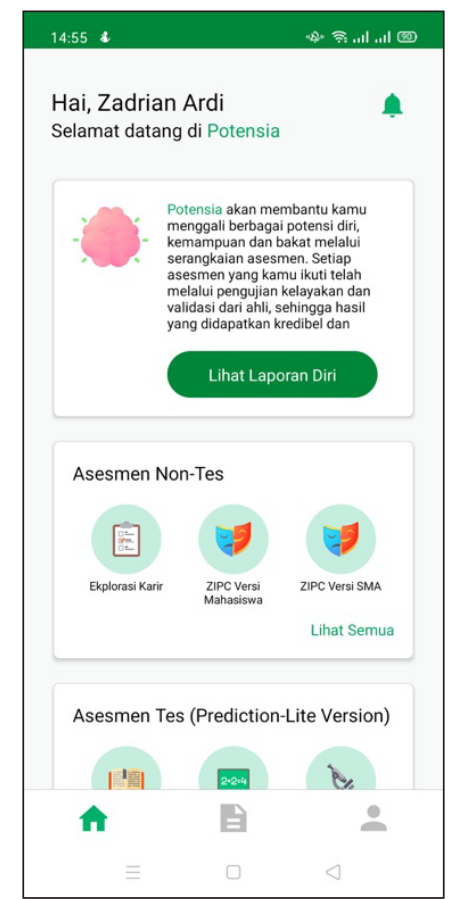

Fig. 3. Fig. 4 POTENSIA application home screen display 


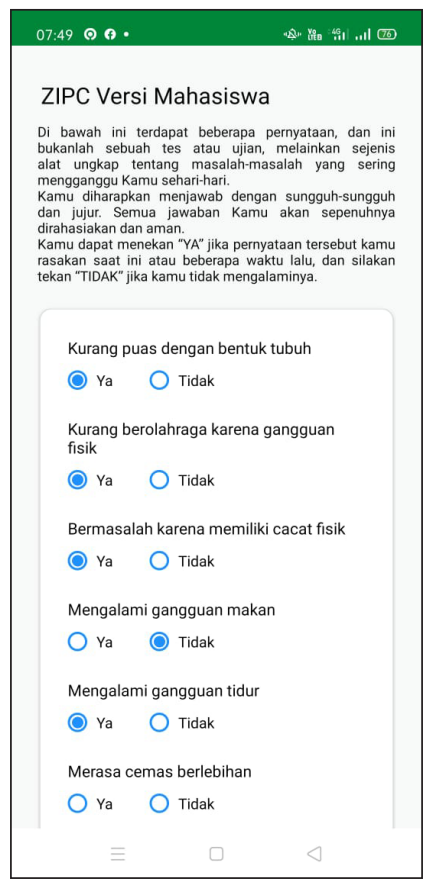

Fig. 4. ZIPC features on POTENSIA

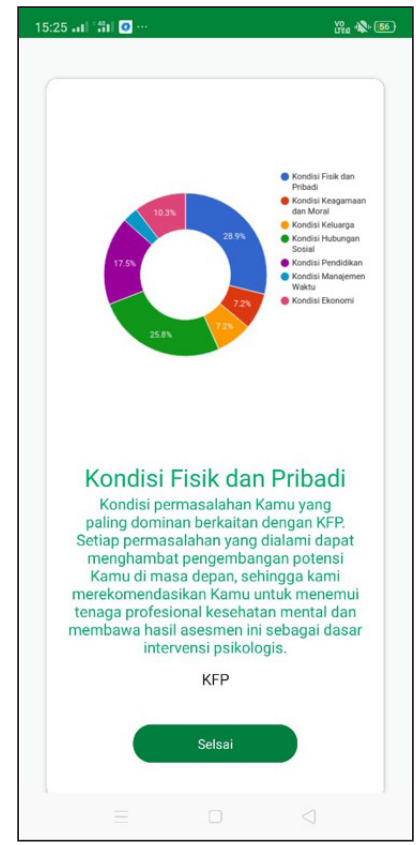

Fig. 5. The results of mental health assessment conditions on the ZIPC feature 


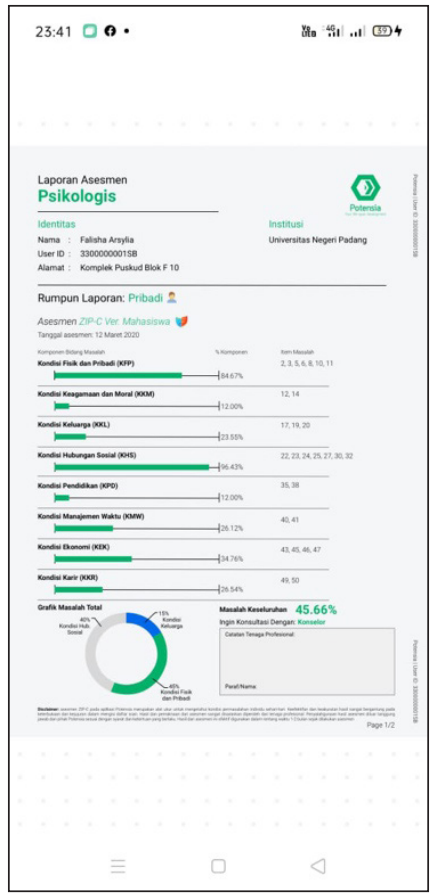

Fig. 6. Assessment reports that can be accessed by users and counselors

As seen in Figure 4, the user can fill in the ZIPC measuring instrument according to the conditions he is experiencing. These results will be obtained shortly after the user has finished filling out the instrument. The data from the instrument entry will be processed immediately and can be accessed by the user. The report can also be accessed by professionals whom the previous user has selected according to the referral code. This condition can only occur with the client's approval or on the condition that the application has collaborated with the agency that provides counseling services.

The report results will be used as a counselor as a basis for determining and planning counseling services. In addition, the counselor can provide intervention and follow-up based on the user's achievement of the assessment results. The client's condition can be seen periodically by the counselor with a precise timestamp so that monitoring of the data on the development of the client's mental health condition can be carried out longitudinally or continuously. The follow-up and reports will also be recorded in the application database and can be reused by counselors.

\subsection{Validity}

In knowing the relevance of the elements in the application with the components that should exist in the psychological assessment process, testing is carried out through expert judgment. The experts involved in this process have produced many psychological measuring tools in Indonesia and are widely used. In the process, experts are asked 
to study the application blueprint and access the application as a whole, both from the user's side and from the administrator's side.

The data obtained from the expert judgment process is then analyzed through Aiken's V. This process produces the Aiken coefficient, which describes the agreement conditions between each expert on the assessed application. This process will generate the validity conditions of the application through five dimensions, namely relevance, efficiency, effectiveness, impact, and attractiveness as seen in Table 2.

Table 2. Aiken's V coefficient for validity assessment of POTENSIA apps

\begin{tabular}{|l|c|c|}
\hline \multicolumn{1}{|c|}{ Dimensions } & Aiken's V Coefficient & Validity Interpretation \\
\hline Relevance Dimension & 0.90 & Valid \\
\hline Efficiency Dimension & 0.95 & Valid \\
\hline Effectiveness Dimension & 0.95 & Valid \\
\hline Impact Dimension & 0.85 & Valid \\
\hline Attractiveness Dimension & 0.95 & Valid \\
\hline Mean & 0.92 & Valid \\
\hline
\end{tabular}

In general, when viewed from the acceptance value of Aiken's V coefficient, all dimensions measured from the application show valid conditions $(>0.8)$. There is only one dimension at the threshold of acceptance of Aiken's $V$ coefficient, namely the impact dimension. Overall application developed is considered valid by the expert. In other words, the application in terms of content, content, and face is reliable for measuring or assessing the psychological condition of the user.

On the other hand, to find out the application acceptance index from the counselor's side, testing is also carried out by involving dimensions according to the counselor's needs. Dimensions measured to determine the acceptance index include format, language usage, content, efficiency, effectiveness, and impact. This measurement will also directly prove that the application can indeed be used by counselors in the process of preparing and planning counseling services, both as a baseline for user data and program preparation regularly.

Table 3. Aiken's V coefficient for counselor's acceptability of POTENSIA apps

\begin{tabular}{|l|c|c|}
\hline \multicolumn{1}{|c|}{ Dimensions } & Aiken's V Coefficient & Praticality Interpretation \\
\hline Assessment Format & 0.95 & Acceptable \\
\hline Language Usage & 0.80 & Quite Acceptable \\
\hline Assessment Content & 0.95 & Acceptable \\
\hline Efficiency Dimension & 0.85 & Acceptable \\
\hline Effectiveness Dimension & 0.93 & Acceptable \\
\hline Impact Dimension & 0.85 & Acceptable \\
\hline Mean & 0.89 & Acceptable \\
\hline
\end{tabular}

The test results prove that all the dimensions measured are considered acceptable by the counselor user as the user of the assessment data as seen in Table 3. There is 
only one dimension (language usage) right on the threshold of acceptance of Aiken's $\mathrm{V}$ index. As a user of assessment data, counselors have good acceptance of applications used in service planning efforts and counseling service baseline data. There is one dimension that is at quite an acceptable level, and after being explored, this dimension is related to the rules of using language on the instrument. The follow-up to the condition of using the language is to simplify the sentence again in the assessment.

In addition, from the dimensions of efficiency and assessment format, counselors as data users also consider that the POTENSIA application can be relied on in the assessment process during the Covid-19 pandemic. The limited mobility of student users to visit the counseling service center is considered by college counselors as a challenge by the POTENSIA application. This is also revealed from the application practicality data in Table 4.

\subsection{Practicality}

Measurement of the practicality of the application was carried out on 638 respondents who had used the application to conduct online psychological assessments. This measurement is done by asking the user to fill out the AMMS instrument with four dimensions: behavioral intention, substitutive, complementary, and personal innovativeness. All of these dimensions will describe the overall user perception of the application.

Testing using Rasch Model Analysis produces an index that generally explains that the application is acceptable and practical according to the user. User acceptance is proven by all the items tested, showing a rescaling logit value above 40 points. In addition, the acquisition of the logit coefficient value means that there is a positive tendency for users to assess the POTENSIA application.

Table 4. The practicality of POTENSIA apps based on AMMS analysis using rasch measurements

\begin{tabular}{|l|l|c|c|c|}
\hline \multicolumn{1}{|c|}{ Items } & \multicolumn{1}{|c|}{ Construct } & $\begin{array}{c}\text { Logit } \\
\text { Value }\end{array}$ & $\begin{array}{c}\text { Rescaling } \\
\text { Logit Value }\end{array}$ & $\begin{array}{c}\text { Outfit } \\
\text { MNSQ }\end{array}$ \\
\hline $\begin{array}{l}\text { I want to access the mental health assessment } \\
\text { services if I feel uncomfortable (A1) }\end{array}$ & $\begin{array}{l}\text { Behavioral } \\
\text { Intention }\end{array}$ & -0.89 & 43.78 & 1.2854 \\
\hline $\begin{array}{l}\text { I take the online psychological assessment on the } \\
\text { application easily (A2) }\end{array}$ & $\begin{array}{l}\text { Behavioral } \\
\text { Intention }\end{array}$ & -0.03 & 46.43 & 1.0532 \\
\hline $\begin{array}{l}\text { I can easily reveal my current personal condition } \\
\text { through the application (A3) }\end{array}$ & Subtitutive & 1.12 & 57.83 & 1.1659 \\
\hline $\begin{array}{l}\text { This application can maintain the confidentiality } \\
\text { of my mental health condition well (A4) }\end{array}$ & Subtitutive & 0.92 & 55.98 & 1.0343 \\
\hline $\begin{array}{l}\text { I can find out my mental health condition before } \\
\text { seeing a counselor (A5) }\end{array}$ & Complementary & 0.19 & 51.25 & 0.8215 \\
\hline $\begin{array}{l}\text { I can monitor my mental health condition } \\
\text { through the app (A6) }\end{array}$ & Complementary & 0.49 & 53.12 & 0.8954 \\
\hline
\end{tabular}


Table 4. The practicality of POTENSIA apps based on AMMS analysis using rasch measurements (Continued)

\begin{tabular}{|l|l|l|c|c|}
\hline \multicolumn{1}{|c|}{ Items } & \multicolumn{1}{|c|}{ Construct } & $\begin{array}{c}\text { Logit } \\
\text { Value }\end{array}$ & $\begin{array}{c}\text { Rescaling } \\
\text { Logit Value }\end{array}$ & $\begin{array}{c}\text { Outfit } \\
\text { MNSQ }\end{array}$ \\
\hline $\begin{array}{l}\text { Almost all of my mental health conditions can be } \\
\text { known through the application (A7) }\end{array}$ & Subtitutive & 0.33 & 52.67 & 0.8431 \\
\hline $\begin{array}{l}\text { I can bring the results of the assessment into the } \\
\text { counseling session (A8) }\end{array}$ & $\begin{array}{l}\text { Personal } \\
\text { Innovativeness }\end{array}$ & -0.49 & 45.64 & 0.5291 \\
\hline I tend to use the latest features in the app (A9) & $\begin{array}{l}\text { Personal } \\
\text { Innovativeness }\end{array}$ & -0.32 & 44.43 & 1.4382 \\
\hline I can easily adapt to the application (A10) & $\begin{array}{l}\text { Personal } \\
\text { Innovativeness }\end{array}$ & -0.97 & 40.31 & 1.5057 \\
\hline
\end{tabular}

When analyzed on each item, it can be observed that users find it easy to express their condition through an online psychological assessment on the POTENSIA application; this is evidenced by the acquisition of a logit value of 1.12 and a rescaling logit coefficient of 57.83. In probability, the possibility of users to continue using the application can be reflected in the acquisition of behavioral intention aspects, especially in the desire to conduct an assessment if they feel uncomfortable, with a rescaling logit coefficient of 43.78. Overall, the MNSQ outfit value also shows acceptable conditions, this strengthens the assumption that users tend to have no problems using the application or the usage error rate is relatively low.

\subsection{Effectivity}

The effectiveness of POTENSIA application is known by measuring the strength and ability of the application in measuring the user's psychological condition. The instrument used in this measurement is ZIPC which has been included in the application and is one of the main features of POTENSIA apps. The strength of the construct and the acquisition of factor coefficients from the instrument indicate the POTENSIA's ability to carry out psychological assessments accurately. Factors in describing and predicting user conditions are the primary domain of application effectiveness in knowing the user's mental health condition.

Table 5. Model fit measurement of ZIPC instrument on POTENSIA application

\begin{tabular}{|l|c|c|c|}
\hline \multicolumn{5}{|c|}{ Chi-square test } \\
\hline \multicolumn{1}{|c|}{ Model } & $\mathbf{X}^{\mathbf{2}}$ & df & p \\
\hline Baseline model & 4826.036 & 435 & \\
\hline Factor model & 1141.181 & 377 & $<.001$ \\
\hline
\end{tabular}

Testing the model through Chi-square proves that significantly the null hypothesis can be rejected as seen in Table 5. This condition proves that all the items contained in the assessment are the same construct and support each other. In other words, the assessment can provide a holistic picture of the user's condition in terms of Physical Issues (PH), Personal Issues (PS), Religious and Moral Issues (RG), Social Relations (SO), Family Issues (FM), Time Management (TM), Education (ED), Economic Issues (EC), Career (CA). 


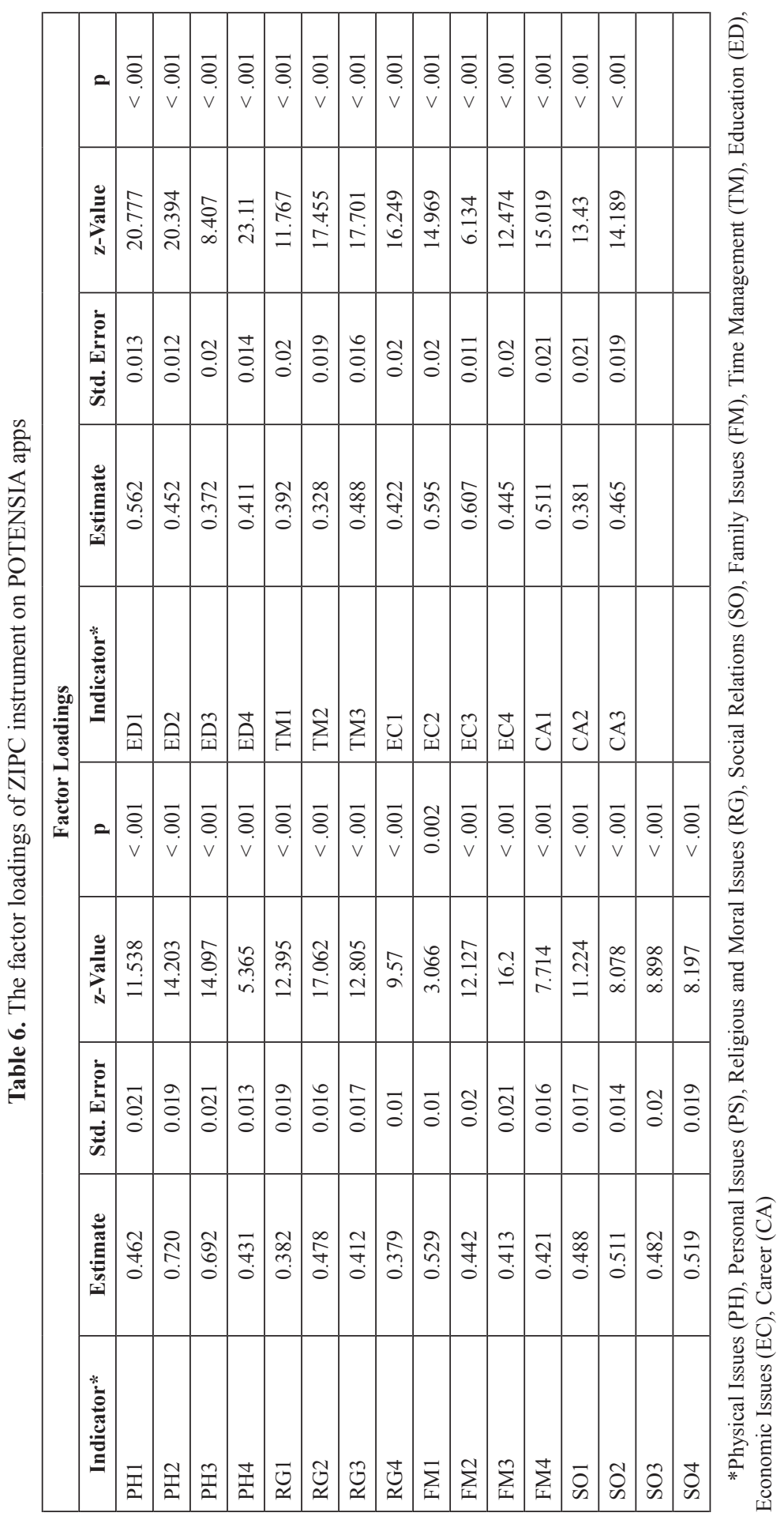


If analyzed from the point of view of factor loadings on each item from Table 6, it can be seen that all items have a good construct in describing individual mental health conditions. If analyzed based on estimated factor loadings and their relation to standard scores, it can be interpreted that there is a significant correlation between indicators and their latent constructs. On the other hand, the standard score explains the magnitude of the deviation between individuals with various z-value coefficients, especially on the education indicator, which contains the desire to immediately change majors (ED1) and feel uncomfortable with the current major (ED2). Based on the relationship between indicators and latent constructs and expected values can explain the mental health condition of students well. With this condition, it can be said that the instruments contained in the application can effectively measure the mental health condition of students and can contribute to planning and baseline data in counseling services in universities.

\section{Conclusion}

The intensity and density of the learning process in higher education make students generally experience pressure and burdens that lead to academic stress conditions. After the emergence of the Covid-19 pandemic, changes in construction and learning atmosphere also require students to make changes in the learning process at universities immediately $[26,32]$. These conditions add to a series of student pressures that lead to decreased productivity and academic achievement. The problem of academic stress has become one of the main focuses of the services of counselors and mental health professionals in universities.

However, with limitations and low mobility conditions during the Covid-19 pandemic, the initial assessment and monitoring of students' mental health conditions were hindered. This condition requires innovation and the development of psychological assessments that can reach students wherever they are and in a fast time. With this phenomenon, it is necessary to develop an online psychological assessment application that is mobile and accessible to students, which in this study is called POTENSIA. The test results of the application prove that the POTENSIA application is reliable in measuring the mental health condition of students, is valid based on expert judgment, and can be practically used. Another important thing about this application is that counselors in universities consider this application to be used as baseline data and an essential indicator in planning and starting counseling services in universities.

\section{$5 \quad$ Acknowledgment}

The authors would like to thank Lembaga Penelitian dan Pengabdian Masyarakat Universitas Negeri Padang for funding this work with a contract number: 962/UN35.13/ LT/2021. 
[1] I. A. Fahsing and K. Ask, "In Search of Indicators of Detective Aptitude: Police Recruits' Logical Reasoning and Ability to Generate Investigative Hypotheses," (in English), J. Police Crim. Psychol., Article vol. 33, no. 1, pp. 21-34, 2018, doi: https://doi.org/10.1007/ s11896-017-9231-3

[2] J. Guo, "Integration of multimedia education into the teaching of college english writing," (in English), Int J Electr Eng Educ, Article 2021, doi: https://doi. org/10.1177/00207209211005258

[3] Y. Y. Sung and C. Y. Kao, "Exploring creativity in the world of five women majoring in science and engineering: How they interpret creativity and how their educational backgrounds affect their creativity," (in Chinese), J. Res. Educ. Sci., Article vol. 64, no. 3, pp. 55-84, 2019, doi: 10.6209/JORIES.201909 64(3).0003

[4] R. P. Dryden et al., "An attribution-based motivation treatment to assist first-generation college students reframe academic setbacks," (in English), Contemporary Educational Psychology, Article vol. 64, 2021, Art no. 101938, doi: https://doi.org/10.1016/j. cedpsych.2020.101938

[5] F. L. Nonglait and E. B. Myrthong, "Rural students transition into higher education in meghalaya: Challenges and coping strategies," (in English), Qual. Rep., Article vol. 26, no. 5, pp. 1663-1677, 2021, doi: https://doi.org/10.46743/2160-3715/2021.4759

[6] I. Alemany-Arrebola, G. Rojas-Ruiz, J. Granda-Vera, and Á. C. Mingorance-Estrada, "Influence of COVID-19 on the Perception of Academic Self-Efficacy, State Anxiety, and Trait Anxiety in College Students," (in English), Frontiers in Psychology, Article vol. 11, 2020, Art no. 570017, doi: https://doi.org/10.3389/fpsyg.2020.570017

[7] N. Hasan and Y. Bao, "Impact of "e-Learning crack-up" perception on psychological distress among college students during COVID-19 pandemic: A mediating role of "fear of academic year loss"," (in English), Children and Youth Services Review, Article vol. 118, 2020, Art no. 105355, doi: https://doi.org/10.1016/j.childyouth.2020.105355

[8] J. Ling and N. R. Zahry, "Relationships among perceived stress, emotional eating, and dietary intake in college students: Eating self-regulation as a mediator," (in English), Appetite, Article vol. 163, 2021, Art no. 105215, doi: https://doi.org/10.1016/j.appet.2021.105215

[9] C. L. Park et al., "Development of emotion regulation across the first two years of college," (in English), Journal of Adolescence, Article vol. 84, pp. 230-242, 2020, doi: https://doi. org/10.1016/j.adolescence.2020.09.009

[10] Z. Ye et al., "Resilience, Social Support, and Coping as Mediators between COVID-19-related Stressful Experiences and Acute Stress Disorder among College Students in China," (in English), Appl. Psychol: Health Well-Being, Article vol. 12, no. 4, pp. 1074-1094, 2020, doi: https://doi.org/10.1111/aphw.12211

[11] C. A. Ştefan, "Self-compassion as mediator between coping and social anxiety in late adolescence: A longitudinal analysis," (in English), Journal of Adolescence, Article vol. 76, pp. 120-128, 2019, doi: https://doi.org/10.1016/j.adolescence.2019.08.013

[12] R. Shao et al., "Prevalence of depression and anxiety and correlations between depression, anxiety, family functioning, social support and coping styles among Chinese medical students," (in English), BMC Psychol., Article vol. 8, no. 1, 2020, Art no. 38, doi: https://doi. org/10.1186/s40359-020-00402-8

[13] A. D. Mancini, M. Westphal, and P. Griffin, "Outside the Eye of the Storm: Can Moderate Hurricane Exposure Improve Social, Psychological, and Attachment Functioning?," (in English), Personality and Social Psychology Bulletin, Article 2021, doi: https://doi. org/10.1177/0146167221990488 
[14] H. Hidayat, Z. Ardi, S. Herawati, and Z. Amrina, "The contribution of internal locus of control and self-concept to career maturity in vocational higher education," KnE Social Sciences, pp. 234-248, 2019. https://doi.org/10.18502/kss.v3i15.4370

[15] H. Hidayat, Z. Ardi, Yuliana, and S. Herawati, "Exploration of the need analysis for technopreneurship scientific learning models in higher vocational education," International Journal of Economics and Business Research, vol. 18, no. 3, pp. 356-368, 2019. https://doi. org/10.1504/IJEBR.2019.102733

[16] Z. Ardi and S. A. Putri, "The analysis of the social media impact on the millennial generation behavior and social interactions," Southeast Asian Journal of Technology and Science, vol. 1, no. 2, pp. 70-77, 2020.

[17] M. Japar, Y. Kardiman, Raharjo, D. N. Fadhillah, and S. Syarifa, "Interactive Mobile Technologies on Civic Education Learning in Higher Education,” vol. 15, no. 3, pp. 84-96, 2021, doi: https://doi.org/10.3991/ijim.v15i03.17509

[18] H. T. T. Nguyen, "Boosting Motivation to Help Students to Overcome Online Learning Barriers in Covid-19 Pandemic: A Case Study," vol. 15, no. 10, pp. 4-20, 2021, doi: https:// doi.org/10.3991/ijim.v15i10.20319

[19] X. Zhang, W. Zhu, S. Kang, L. Qiu, Z. Lu, and Y. Sun, "Association between physical activity and mood states of children and adolescents in social isolation during the COVID-19 epidemic," (in English), International Journal of Environmental Research and Public Health, Article vol. 17, no. 20, pp. 1-12, 2020, Art no. 7666, doi: https://doi.org/10.3390/ ijerph17207666

[20] M. Yu, F. Tian, Q. Cui, and H. Wu, "Prevalence and its associated factors of depressive symptoms among Chinese college students during the COVID-19 pandemic," (in English), BMC Psychiatry, Article vol. 21, no. 1, 2021, Art no. 66, doi: https://doi.org/10.1186/ s12888-021-03066-9

[21] A. M. Hasratian, H. O. Nordberg, A. E. Meuret, and T. Ritz, "Fear and coping in students during the early stages of the covid-19 pandemic: A combined cross-sectional and longitudinal study," (in English), International Journal of Environmental Research and Public Health, Article vol. 18, no. 12, 2021, Art no. 6551, doi: https://doi.org/10.3390/ijerph18126551

[22] L. Castillo-Cuesta, "Using Digital Games for Enhancing EFL Grammar and Vocabulary in Higher Education,” vol. 15, no. 20, pp. 116-129, 2020, doi: https://oi.org/10.3991/ijet. v15i20.16159

[23] C. Huerta-Guerrero et al., "Kaanbal: A Mobile Learning Platform Focused on Monitoring and Customization of Learning," vol. 16, no. 1, pp. 18-43, 2020, doi: https://doi.org/10.3991/ ijet.v16i01.16483

[24] D. Burns, N. Dagnall, and M. Holt, "Assessing the Impact of the COVID-19 Pandemic on Student Wellbeing at Universities in the United Kingdom: A Conceptual Analysis," (in English), Front. Educ., Article vol. 5, 2020, Art no. 582882, doi: https://doi.org/10.3389/ feduc. 2020.582882

[25] M. J. Savage et al., "Mental health and movement behaviour during the COVID-19 pandemic in UK university students: Prospective cohort study," (in English), Ment. Health Phys. Act., Article vol. 19, 2020, Art no. 100357, doi: https://doi.org/10.1016/j.mhpa.2020.100357

[26] J. Lee, M. Solomon, T. Stead, B. Kwon, and L. Ganti, "Impact of COVID-19 on the mental health of US college students," (in English), BMC Psychol., Article vol. 9, no. 1, 2021, Art no. 95, doi: https://doi.org/10.1186/s40359-021-00598-3

[27] K. Tiaprapong, A. Sirikul, C. Krajangmek, N. Duangthongkul, N. Pandam, and N. Piya-Amornphan, "Awareness of COVID-19 influences on the wellness of Thai health professional students: An ambulatory assessment during the early "new normal" informing policy," (in English), PLoS ONE, Article vol. 16, no. 6 June, 2021, Art no. e0252681, doi: https://doi.org/10.1371/journal.pone.0252681 
[28] J. Kostić, O. Žikić, V. Đorđević, and Ž. Krivokapić, "Perceived stress among university students in south-east Serbia during the COVID-19 outbreak," (in English), Ann. Gen. Psychiatry, Article vol. 20, no. 1, 2021, Art no. 25, doi: https://doi.org/10.1186/s12991-021-00346-2

[29] C. M. Durán Acevedo, J. K. Carrillo Gómez, and C. A. Albarracín Rojas, “Academic stress detection on university students during COVID-19 outbreak by using an electronic nose and the galvanic skin response," (in English), Biomed. Signal Process. Control, Article vol. 68, 2021, Art no. 102756, doi: https://doi.org/10.1016/j.bspc.2021.102756

[30] M. Casacchia et al., "Distance education during COVID 19: an Italian survey on the university teachers' perspectives and their emotional conditions," (in English), BMC Medical Education, Article vol. 21, no. 1, 2021, Art no. 335, doi: https://doi.org/10.1186/s12909-021-02780-y

[31] A. Ouajdouni, K. Chafik, and O. Boubker, "Measuring e-learning systems success: Data from students of higher education institutions in Morocco," (in English), Data in Brief, Data Paper vol. 35, 2021, Art no. 106807, doi: https://doi.org/10.1016/j.dib.2021.106807

[32] A. Shahzad, R. Hassan, A. Y. Aremu, A. Hussain, and R. N. Lodhi, "Effects of COVID-19 in E-learning on higher education institution students: the group comparison between male and female," (in English), Qual. Quant., Article vol. 55, no. 3, pp. 805-826, 2021, doi: https:// doi.org/10.1007/s11135-020-01028-Z

[33] N. Tuaycharoen, "University-Wide Online Learning During COVID-19: From Policy to Practice," (in English), Int. J. Interact. Mob. Technol., Article vol. 15, no. 2, pp. 38-54, 2021, doi: https://doi.org/10.3991/ijim.v15i02.18143

[34] A. Sangodiah, C. R. Spr, N. A. Jalil, A. Y. Hui Nee, and S. Subramaniam, Investigation on Mental Health Well-Being for Students Learning from Home Arrangements Using Clustering Technique, vol. 220, pp. 113-122, 2021. https://doi.org/10.1007/978-3-030-74605-6 14

[35] C. A. Azlan et al., "Teaching and learning of postgraduate medical physics using Internet-based e-learning during the COVID-19 pandemic - A case study from Malaysia," (in English), Phys. Med., Article vol. 80, pp. 10-16, 2020, doi: https://doi.org/10.1016/j. ejmp.2020.10.002

[36] J. Rucker, S. Steele, J. Zumwalt, and N. Bray, "Utilizing Zoom Breakout Rooms to Expose Preclerkship Medical Students to TeleMedicine Encounters," (in English), Med. Sci. Educ., Article vol.30, no. 4, pp. 1359-1360, 2020, doi: https://doi.org/10.1007/s40670-020-01113-w

[37] C. A. Bolu et al., "Engineering Students' Virtual Learning Challenges during COVID19 Pandemic Lockdown: A Case Study," 2020: Institute of Electrical and Electronics Engineers Inc., doi: 10.1109/WEEF-GEDC49885.2020.9293681. [Online]. Available: https://www.scopus.com/inward/record.uri?eid=2-s2.0-85099311069\&doi=10.1109\%2fWEEF-GEDC49885.2020.9293681\&partnerID=40\&md5=d926b1b175d7f9611 ac2ecfc179a72bf

[38] Z. Ardi, Neviyarni, and Daharnis, "Konselo app: The future of distance counselling and therapy applications based on android technology," (in English), International Journal of Innovation, Creativity and Change, Article vol. 5, no. 6, pp. 231-244, 2019. [Online]. Available: https:// www.scopus.com/inward/record.uri?eid=2-s2.0-85084436048\&partnerID $=40 \& \mathrm{md} 5=$ fa9c4d31b0195e977e60383f7350523c

[39] Z. Ardi, "An analysis of education principle implementation in an online counseling approach: a preliminary study based on analysis using the Rasch model," COUNS-EDU: The International Journal of Counseling and Education, vol. 4, no. 2, pp. 59-68, 2019. https://doi.org/10.23916/0020190418720

[40] P. R. Arjun and A. Srivastava, "EDUCO: An Augmented Reality Application to Enrich Learning Experience of Students for History and Civics Subjects," 2020: Association for Computing Machinery, Inc, pp. 81-84, doi: 10.1145/3380867.3426217. [Online]. Available: https://www.scopus.com/inward/record.uri?eid=2-s2.0-85096927674\&doi=10.1145\%2f33 80867.3426217\&partnerID=40\&md5=d9ed0ce9013d7a56aaba8a9cff820c61 
[41] E. Lógó and V. Orbulov, "Case study for product development innovation based on design thinking approach, demonstrated by smart furniture project," (in English), Period. Polytech. Civ. Eng., Article vol. 65, no. 2, pp. 397-408, 2021, doi: https://doi.org/10.3311/PPci.17321

[42] W. D. Sulistyo, M. N. L. Khakim, N. Jauhari, and R. D. Anggraeni, "Fun Learning History: Explore the History of Water Sites Based on Android," vol. 16, no. 7, pp. 105-118, 2021, doi: https://doi.org/10.3991/ijet.v16i07.21215

[43] Z. Ardi, R. D. Febriani, I. Ifdil, and A. Afdal, "Android "karirKu" Software Development for Exploration of Career Trends based on Personality Types," in Journal of Physics: Conference Series, 2019, vol. 1339, 1 ed., doi: 10.1088/1742-6596/1339/1/012123. [Online]. Available: https://www.scopus.com/inward/record.uri?eid=2-s2.0-85077823893\&doi=10.1088\%2f1742-6 596\%2f1339\%2f1\%2f012123\&partnerID=40\&md5=900e11c7db19df8e09eb2ee8cc057824

[44] Z. Ardi, I. Ifdil, and M. Maysitoh, "Development and validation of the Zadrian-Ifdil Problem Checklist (ZIPC) for college students," International Journal of Technology, Innovation and Humanities, vol. 1, no. 1, pp. 41-50, 2020. https://doi.org/10.29210/881601

\section{$7 \quad$ Authors}

Zadrian Ardi is a Senior Lecturer of Guidance and Counseling Department, Faculty of Education, Universitas Negeri Padang, Indonesia. His area of research and expertise is mental health, assessment in counseling and technology in counseling.

Hendra Hidayat is a Lecturer of Electronic Engineering Education Department, Faculty of Engineering, Universitas Negeri Padang, Indonesia. His area of research is technical vocational and education training, and engineering education.

Ifdil Ifdil is an Associate Professor of Guidance and Counseling Department, Faculty of Education, Universitas Negeri Padang. His area of research is traumatic counseling, addiction and mental health.

Yan Guspriadi is a research member of Potensia Institute, Indonesia. The focus and scope of this institue is technology development and application in counseling.

Siti Azizi Fauziyyah is a research member of Potensia Institute, Indonesia. The focus and scope of this institue is technology development and application in counseling.

Article submitted 2021-05-29. Resubmitted 2021-07-01. Final acceptance 2021-07-02. Final version published as submitted by the authors. 